\title{
Black Lives Matter a través de las series de televisión estadunidenses Black Lives Matter through U.S. TV Series
}

\author{
JuAn Vicente Iborra Mallent ${ }^{*}$
}

\section{RESUMEN}

En el presente artículo me propongo explorar cómo las demandas del movimiento antirracista afroamericano black lives matter se han reflejado en las series de televisión estadunidenses. En los últimos años se ha incrementado considerablemente el número de series que incorporan temáticas afroamericanas, situación similar a la manera en que durante la década de los años setenta, coincidiendo con el auge del black power, se dio un boom en el género del blaxploitation. Así, me interesa abordar cómo en las narrativas presentadas se incorpora la denuncia social desde un enfoque interseccional de clase, género y raza.

Palabras clave: series de televisión, cultura afroamericana, capitalismo racial, violencia policial.

\section{ABSTRACT}

This article proposes an exploration of how the demands of the Afro-American anti-racist movement Black Lives Matter have been reflected in U.S. television series. In recent years, the number of series that include Afro-American themes has increased considerably, similar to what happened in the 1970s when the rise of black power sparked a boom in Blaxploitation. The author deals with how the series' narratives incorporate social denunciation, using an intersectional class, gender, and race approach.

Key words: television series, Afro-American culture, racial capitalism, police violence.

* Maestría en Estudios Latinoamericanos, Universidad Nacional Autónoma de México, <juan.v.iborra@gmail. com>. 


\section{INTRODUCCIÓN}

La proliferación de series de televisión con temática afroamericana emitidas en Estados Unidos coincide con la emergencia de un nuevo ciclo de movilizaciones y protestas cuya seña más notable ha sido el movimiento político black lives matter (BLM, las vidas negras importan). Por medio de protestas, campañas y manifiestos, este movimiento ha sido capaz de articular una multiplicidad de colectivos afroamericanos que ostentan un abanico de críticas comunes: la violencia policial, el complejo industrial carcelario, el tránsito de la escuela a la cárcel (school-to-prison pipeline), la desigual distribución de la riqueza y la precariedad, la violencia sexual contra las mujeres racializadas, la inseguridad en los barrios, las reparaciones históricas, entre otras. Esta plataforma mediática ha servido para articular tanto visiones reformistas como revolucionarias que proponen desde la mejora de la vida en las prisiones o incluso su abolición, hasta el integracionismo de clase y la autodeterminación política y económica.

A primera vista, el incremento de series de televisión que abordan temáticas relacionadas con la forma de vida de la población afroamericana pudiera reflejar una capitalización por parte de productoras y plataformas digitales de emisión de video (Netflix, HBO, Amazon, Hulu) de las demandas que las movilizaciones de los últimos años han puesto en discusión entre la opinión pública estadunidense. Sin embargo, a lo largo del artículo trataré de complejizar cómo mediante las narrativas presentes en diversas series de televisión se generan espacios de autorrepresentación que disputan los marcos hegemónicos de representación, y definen imaginarios que moldean la manera en que los colectivos afroamericanos se conciben, identifican y cuestionan la realidad al apropiarse de las formas de representación dominantes y, al mismo tiempo, proyectan deseos, incertidumbres, sensibilidades y modos de existencia.

En el primer apartado retomaré como antecedente de convergencia entre industria cinematográfica y ciclo de movilización social el caso del género fílmico blaxploitation en la década de los años setenta, que coincidió con el movimiento black power en defensa de los derechos sociales y políticos de la población afroamericana. Más que pretender un análisis exhaustivo de lo que significó el blaxploitation, situar este precedente me permite recuperar las discusiones teóricas que realizaron los estudios culturales negros respecto a la relación industria/movimientos sociales, y que de algún modo puede aportar ciertas claves respecto a la relación que se ha establecido en los últimos años entre la industria de las series de televisión y el movimiento BLM. En los siguientes apartados trataré de problematizar cómo en los últimos años se han incorporado en la industria de las series de televisión narrativas relacionadas con la historia y cultura afroamericanas, la brutalidad policial y el complejo industrial 
carcelario desde un enfoque interseccional de sexo, género, clase y raza, que coinciden con las demandas de BLM. ${ }^{1}$

La selección de series presentadas en este artículo es resultado de un intento por abarcar el mayor número de producciones que se han estrenado con posterioridad al surgimiento de BLM (algunas un poco antes). Del mismo modo, quiero puntualizar que mi intención no es hacer un análisis pormenorizado del contenido de estas series; dejo en manos del lector la posibilidad de verlas, y establecer un diálogo con las problemáticas que se presentan a lo largo del texto. Aunque la selección dista de comprender todas las series emitidas en los últimos años, he pretendido incorporar el mayor número, desde géneros y temáticas diversas, y que sin embargo abordan cuestiones en común como la brutalidad policial o el complejo industrial carcelario, presentes en el origen de las demandas de BLM. En ese sentido, lejos de considerar industria cultural de masas y movimiento social como dos compartimentos estancos, quiero reflejar su continua simbiosis e interacción.

A lo largo del texto, trataré de argumentar cómo estas interacciones intervienen en la dialéctica que se produce entre industria televisiva y movimiento social y cómo se generan espacios de coproducción que complejizan los vínculos existentes entre las distintas esferas (audiencia, realizadores, productores).

\section{Blaxploitation}

Anteriormente, algunos autores (Guerrero, 2012; Robinson, 1998) consideraron que el género fílmico blaxploitation, que tuvo su auge a inicios de la década de los setenta, fue la respuesta de la industria cinematográfica frente al auge del black power y que, por tanto, la industria supo ensamblar ciertas narrativas como producto cultural vendible hacia determinados segmentos de la población. A pesar de que este género creó oportunidades laborales para actores y realizadores negros y terminó con estereotipos ampliamente extendidos respecto al carácter sumiso y pasivo de la población afroamericana, los reemplazó por nuevos en torno a la masculinidad negra hegemónica, la hipersexualización de la mujer, criminales violentos y guetos en donde predominaba el tráfico de drogas al margen de la ley (Terry, 2012).

\footnotetext{
${ }^{1}$ Las demandas principales de BLM se encuentran "Una visión para las vidas negras. Demandas políticas para el poder negro, la libertad y la justicia". En este documento se analizan cuestiones relacionadas con la violencia contra las comunidades negras, la diversidad sexual, el militarismo y la supremacía blanca, las reparaciones por la esclavitud y las desigualdades estructurales, la autodeterminación política y el control comunitario, la criminalización, el encarcelamiento y asesinato de gente negra así como la justicia económica. Véase Movement for Black Lives (2016: 225-232).
} 
El académico afroamericano Cedric J. Robinson llegó a afirmar que el género blaxploitation había degradado la industria al postrarse a las exigencias políticas y del mercado; a los actores, al mostrarse más cercanos al dinero recibido que a aquellas clases bajas que caricaturizaban en sus películas, y a la audiencia, que era sometida a una parodia de las aspiraciones del movimiento de liberación negra (Robinson, 1998). Estas críticas, que provenían en su mayoría de intelectuales y activistas del nacionalismo negro (black nationalism), fueron desdeñadas por aquellos afroamericanos que participaron activamente en la industria, al considerar orgullosamente las oportunidades que les había abierto el género (Lawrence, 2007). Otros autores apuntan hacia cómo, con sus limitaciones, blaxploitation impulsó variaciones respecto a figuras clásicas al propiciar espacios de reapropiación y representación en términos raciales y de género (Benshoff, 2000).

En ese sentido, es importante plantear cómo esta discusión influyó en el campo de los estudios culturales negros, pues al reflejar opiniones divergentes, evidenció que no hay una audiencia negra monolítica, puesto que asimila, resiste o se apropia del texto de maneras diversas (Reid, 2000; Kraszewski, 2002). En los mismos términos, no se puede negar que la emergencia de una espectacular y llamativa estética negra (Ongiri, 2009) por medio de las manifestaciones políticas, artísticas y culturales del periodo de liberación negra fue determinante en la consolidación de una audiencia afroamericana que convergería con una industria en expansión, que supo sacar rédito al momento de organización y efervescencia social, lo que al mismo tiempo contribuyó a la articulación dialéctica de ambas esferas.

El antecedente del blaxploitation nos sirve como referente desde el cual podemos complejizar la expansión y recepción de las series de televisión afroamericanas al calor del contexto político, económico y social actual. El creciente auge de series que incorporan temáticas afroamericanas, lejos de reflejar un intento controlado por incorporar de manera instrumental ciertos discursos y problemáticas, responde a la configuración de espacios de coproducción que se dan a partir de la interacción entre audiencia, productores y realizadores (Raiford y Raphael-Hernandez, eds., 2017). La denuncia de la brutalidad policial y la industria carcelaria ha adquirido un protagonismo esencial, de modo que las fronteras de los contenidos que se construyen mediante las series de televisión son porosas y cambiantes, incorporan y deshacen narrativas, y éstos, a la vez, vienen determinados por los acontecimientos.

Los productores y actores afroamericanos incorporan historias y denuncias, impulsados tanto por su compromiso social como por la interacción con los usuarios de las plataformas digitales. Un reciente ejemplo sería el del director y actor principal de la serie Atlanta (2016-), Donald Glover, quien hace unas semanas estrenó el polémico y exitoso videoclip de la canción "This is America", con lo que se generó 
un amplio debate en redes sociales porque aborda de manera cruda y directa la violencia policial en Estados Unidos. ${ }^{2}$ Las redes sociales acortan las distancias y hacen posibles dichas interacciones, que no pueden esquivarse pues se han convertido en un elemento publicitario fundamental en la era digital, ya que construye una cierta imagen hiperreal de democracia participativa que oculta la manera en que una agenda socialmente comprometida se convierte en la forma mediante la que la industria cultural privatiza nuevos contenidos y formatos.

Al crearse nuevos espacios de autorrepresentación se ha contribuido a la exposición de imágenes más precisas y acordes con la realidad afroamericana, pues la situacionalidad de ciertas problemáticas cotidianas relacionadas con el género, la diversidad sexual o la adolescencia se imbrica con aspectos estructurales de la dominación que el capitalismo racial (Robinson, 1983; Kelley, 2017) impone sobre las corporalidades negras. De este modo, se dibuja la potencialidad crítica de la denuncia en un medio amplio de difusión, algo que hace unos años era difícil de imaginar. La manera en que televisión y activismo se constituyen mutuamente es difícil de delimitar, teniendo en cuenta la naturaleza mediática que el movimiento BLM tuvo desde sus orígenes. ${ }^{3}$

Sin embargo, en el presente artículo buscaré advertir cómo ciertas demandas y representaciones han ido impregnando las producciones televisivas señaladas y desde dicha puesta en escena, pretendo analizar aspectos centrales del régimen de dominación capitalista racial que opera tanto a nivel molecular como estructural. Para ello, me propongo retomar fragmentos de diversas series que problematicen y visibilicen las interacciones entre imaginario, denuncia social y actualidad política.

\section{LA VISIBILIZACIÓN DE LA HISTORIA Y CULTURA AFROAMERICANAS}

Si hace poco más de cien años la película muda The Birth of a Nation (D.W. Griffith, 1915) promovía abiertamente el racismo y presentaba a los miembros del movimiento supremacista blanco Ku Klux Klan como héroes, hoy el cine y la televisión se han convertido en un terreno por disputar para las minorías perseguidas y racializadas durante siglos de colonialismo, cuya historia ha sido invisibilizada. El propio movimiento

\footnotetext{
${ }^{2}$ El videoclip fue un éxito pues superó los cuarenta y siete millones de reproducciones en YouTube en menos de tres días.

${ }^{3}$ El movimiento se inicia a partir de la difusión masiva del hashtag \#BlackLivesMatter tras la absolución a George Zimmerman, acusado por el asesinato del adolescente afroamericano Trayvor Martin en 2013. En 2014, BLM adquiere importancia nacional tras el asesinato de Michael Brown (en Ferguson, Missouri) y Eric Garner (en la Ciudad de Nueva York) y el estallido de protestas y levantamientos. BLm no es una organización jerárquica y las redes sociales se han convertido en un punto central de articulación para el movimiento. Al mismo tiempo, la presencia de activistas de BLM en televisión y redes sociales lo ha marcado desde sus inicios.
} 
BLM ha situado las reparaciones por la esclavitud y las condiciones de desigualdad estructurales como un punto central de sus demandas, e intelectuales del movimiento como Ta-Nehisi Coates han vuelto a poner la historia afroamericana en el centro del debate público con el objetivo de discutir, tal y como hicieran hace más de cien años Frederick Douglass o W.E.B. du Bois, los orígenes de las condiciones de explotación y marginalidad de la población afroamericana, tanto en el periodo esclavista como en la historia estadunidense posterior a la abolición. Al mismo tiempo, la visibilización de movimientos culturales, políticos y sociales afroamericanos se ha convertido en una herramienta desde la cual se pueda presentar esa otra historia que fue borrada durante décadas por la historia oficial estadunidense, donde el afroamericano en la pantalla era folklorizado y estereotipado.

La historia de la esclavitud en Estados Unidos ha sido retomada en los últimos años en la gran pantalla por películas como 12 años de esclavitud (2013) o The Birth of a Nation (2016). Las atrocidades perpetradas durante el periodo esclavista han sido, de igual manera, expuestas de forma explícita en series de televisión como Roots (2016) o Underground (2016-2017).

Roots es un remake de la célebre serie de 1977 que, basada en la novela homónima de Alex Haley, narra a modo de saga la historia de una familia, desde la captura y esclavización forzada en el oeste de África del joven guerrero mandinga Kunta Kinte, hasta la abolición de la esclavitud tras la Guerra de Secesión. La historia recoge las formas de vida tradicionales en Juffure (Gambia), las terribles condiciones del comercio de esclavos durante el pasaje intermedio, las subastas de esclavos y el trabajo en las plantaciones. A lo largo de varias generaciones se muestran las formas cotidianas de resistencia y de organización tanto en la familia como en la plantación, así como la huida de los esclavos como la forma más explícita de resistencia. Al mismo tiempo, se incide a lo largo de toda la serie en la resistencia de género frente a la violencia sexual, pues aparece de forma explícita la brutal violencia a la que las mujeres fueron expuestas.

Underground refleja la historia del ferrocarril subterráneo que en los años anteriores al estallido de la Guerra Civil estadunidense conformó toda una red clandestina de rutas y refugios por la que los esclavos escapaban hacia el norte y Canadá desde las plantaciones del sur. En esta serie, se retoman algunas figuras fundamentales de la historia del ferrocarril como Harriet Tubman, quien ayudaría a escapar a decenas de esclavos y tras la Guerra Civil lucharía por el sufragio femenino. La propia Tubman aparecerá de nuevo en un episodio de la serie Black-ish (2014-), en la que un padre afroamericano de clase media-alta intenta transmitir a sus hijos cierto sentido de identidad y conciencia racial. La serie trata constantemente de discutir ciertos estereotipos existentes respecto a la cultura negra en Estados Unidos parodiando percepciones comúnmente extendidas. Asimismo, en varios episodios se retoman fragmentos de 
la historia afroamericana: la trata de esclavos, la marcha sobre Washington en la que Martin Luther King pronunció su histórico discurso "I have a dream" o el Black Panther Party y la autoorganización armada, siempre en clave de humor.

También en Luke Cage (2016-) encontramos constantes referencias a la historia afroamericana. Centrada en Harlem (Nueva York), el protagonista es un superhéroe afroamericano atípico que se preocupa por la comunidad, lo cual lo lleva a enfrentarse con aquellos que tratan de emprender un nuevo "renacimiento de Harlem" 4 a partir de actividades criminales. La colusión entre la política Mariah Dillard y su primo Cottonmouth, líder mafioso y propietario del club nocturno Harlem's Paradise se cristaliza como un intento de obtención de control, poder, riqueza y autodeterminación y al mismo tiempo como forma de superar el martirio sufrido históricamente por la población afroamericana. Esta posibilidad de mejora y progreso viene impulsada por la construcción del complejo de viviendas The Crispus Attucks Complex ${ }^{5}$ para la población negra del barrio; no obstante, Luke Cage revela que este proyecto es parte de una operación criminal y especulativa. El capitalismo negro criminal, lejos de constituir una alternativa a la burocracia, la corrupción y la brutalidad policial, termina reproduciendo las mismas prácticas sobre las que se sostiene el capitalismo racial.

Por el contrario, a partir de la figura de Luke Cage se construye un concepto alternativo de heroicidad que discute la instrumentalización de la cultura afroamericana por parte de villanos y criminales. Lejos de presentar al personaje como una figura mesiánica o redentora, Luke Cage extiende sus vínculos hacia el grueso de la comunidad, poniendo su fuerza a disposición de la misma, empleándola no para su provecho y prestigio personal sino como un instrumento destinado a la autodefensa colectiva. Harlem, entonces, se retoma como un símbolo de autoorganización cargado de historia, y se alude constantemente a referentes culturales y literarios afroamericanos.

En la barbería de Pop, un lugar en el que los vecinos se reúnen, la figura del héroe es objeto de discusión a partir de diversos referentes tomados de la historia de la literatura afroamericana: la serie de ficción urbana Kenyatta de Donald Goines, que narra los intentos de un grupo de militantes negros por acabar con el tráfico de drogas en las calles y con el racismo policial, las investigaciones del detective Easy Rawlins en Little Green, de Walter Mosley, o la serie de novelas de género negro escritas por Chester Himes, protagonizadas por los detectives de Harlem, Coffin Ed Johnson y

\footnotetext{
${ }^{4}$ El Renacimiento de Harlem es un movimiento artístico que tuvo lugar en la década de 1920; la pintura, la literatura y el jazz hicieron del barrio un foco de irradiación cultural. Algunas de sus figuras más relevantes fueron Louis Amstrong, Duke Ellington, Zora Neale Hurston, Langston Hugues y Claude McKay.

${ }^{5}$ Crispus Attucks fue un estibador afroamericano asesinado en la masacre de Boston y fue la primera víctima en la llamada Revolución de Estados Unidos, por lo que se le considera un patriota y el primer mártir de la Revolución.
} 
Grave Digger Jones. Entre otras referencias encontramos lecturas apiladas en la habitación de Luke Cage: la novela de 1952 de Ralph Ellison Invisible Man, en la que se reflexiona en torno al nacionalismo negro, el marxismo, la integración afroamericana, así como un informe sobre la rebelión en la cárcel de Attica en el estado de Nueva York en 1971, que terminó con la muerte de cuarenta y tres personas.

Otra serie que resulta relevante en su intento por reflejar la cultura afroamericana es The Get Down (2016-2017). Ambientada en el sur del Bronx (Nueva York) de finales de la década de los setenta, aborda los orígenes del hip hop y sus elementos principales: el breakdance, el MC, el grafiti y el DJ. La serie, además de explorar los inicios de un género musical que se ha expandido mundialmente, ${ }^{6}$ visibiliza aspectos estructurales que ofrecen un panorama del contexto social y político en el que surge: la pobreza y segregación urbana, la criminalización del grafiti, la persecución policial, la especulación inmobiliaria y la remodelación urbana.

Otro aspecto que se explora en la serie es el carácter paliativo de las políticas afirmativas y de inclusión de minorías. En ese sentido, el joven MC Ezekiel dispone de la posibilidad de obtener una beca para cursar estudios universitarios a cambio de negar y criminalizar el arte urbano sobre el que gira su mundo, y cuya persecución es para el alcalde Ed Koch una prioridad en su intento por restaurar "el orden y la ley", así como la seguridad pública, tras los disturbios y saqueos que se registraron a partir del apagón eléctrico de 1977 en algunas zonas de Nueva York. El carácter asistencial y paternalista de dichas políticas se evidencia cuando en varias escenas se revela el racismo estructural que predomina y estigmatiza a los jóvenes del barrio que, lejos de postrarse y aceptar de manera servil las disposiciones disciplinarias, cuestionan el régimen de alianzas políticas y privilegios económicos sobre los que se sostiene. Ezekiel, quien termina perdiendo la oportunidad de la beca, se gana, sin embargo, el cariño y respeto de sus amigos del barrio, a quienes decide no traicionar y defender como forma de camaradería.

\section{BRUTALIDAD POLICIAL Y COMPLEJO INDUSTRIAL CARCELARIO}

Series como Black-ish (2x16), Atlanta, Queen Sugar, Scandal (4x14) han abordado entre sus contenidos la violencia policial contra la población afroamericana en coincidencia

\footnotetext{
${ }^{6}$ También sobre el hip hop se han emitido el drama Empire (2015-), que se centra en una compañía discográfica y la comedia Atlanta (2016-), que narra la historia de dos primos en su intento por triunfar en la escena musical. El soundtrack de Luke Cage está repleto de canciones de hip hop, y el rapero 50 Cent ha producido la serie Power (2014-), en la que también participa como actor. La estética hip hop aparece prácticamente en todas las series de televisión afroamericana emitidas los últimos años.
} 
con tiempos difíciles como los disturbios de Ferguson, o Charlotte (Carolina del Norte). La proliferación de protestas y disturbios por asesinatos de personas afroamericanas, generalmente desarmadas, ha venido acompañada de una denuncia en series como las mencionadas de la brutalidad policial y la impunidad frente a este tipo de sucesos.

A pesar de emitirse en la ultraconservadora cadena Fox, Shots Fired (2017) es una de las series que mejor ha sabido captar algunas de las problemáticas de que hablamos y que el movimiento BLM ha tratado de visibilizar durante los últimos años: la violencia policial contra la población negra, así como la manera en que el racismo opera, tanto en los cuerpos policiales como en las políticas públicas. La investigación de dos detectives afroamericanos del asesinato por parte de un policía negro de un ciudadano blanco destapa el encubrimiento por parte del cuerpo policial del asesinato del adolescente afroamericano Joey Campbell. Durante la investigación se desentrañan alianzas como la del reverendo afroamericano conservador Dupont con la clase política en el poder. La posición de Dupont manifiesta lo que Keeanga-Yamahtta define como "control comunitario" (Taylor, 2017). En las últimas décadas, el control comunitario como forma de organización y control social ha venido acompañado de un "giro pragmático" que ha tenido como consecuencia que los colectivos y las organizaciones sociales afroamericanas participen en contiendas electorales y han obtenido cargos representativos, aunque no se hayan modificado sustancialmente las estructuras económicas y políticas sobre las que se sostiene el régimen de dominación racial y de clase. Este viraje, que se inició a finales de la década de los años sesenta con el auge de las organizaciones de liberación negra, pero que coincidió con una intensificación en las políticas represivas por parte del Estado, operaría inicialmente en un plano local y fue saludado positivamente por el establishment político, que no dudó en promover representantes negros como forma de frenar la insurgencia y fomentar instrumentalmente interlocutores "válidos" con quienes negociar.

La gobernadora Eamons, frente al riesgo de disturbios como respuesta a la violencia policial, trata de negociar con Dupont políticas educativas de carácter afirmativo para estudiantes de barrios marginados, otorgándole el dinero procedente de la creación de un nuevo complejo carcelario. Esta posición que se arroga el reverendo como mediador y canalizador de la opinión pública afroamericana contrasta con la emergencia de nuevos liderazgos y formas de hacer política. La pastora Janae maneja el lenguaje de las redes sociales (Twitter, Instagram, Snapchat), es activista de BLM y usa playeras estampadas con fotografías de figuras históricas del movimiento negro como Rosa Parks o Angela Davis. Desde su templo intenta constituir un espacio de reconciliación, sanación y denuncia del racismo, y pronto se legitima como alternativa en la comunidad frente a la pasividad de Dupont en torno a la violencia policial. 
Sin embargo, el personaje oscila entre el activismo y la negociación política, pues revela sus propias contradicciones ya que dispone de una fuerte capacidad de liderazgo con la cual podría impulsar la rebelión o la negociación política, lo que no permite al movimiento más alternativa que someterse al tutelaje de ciertas figuras. Un momento emblemático de la serie tiene lugar cuando el hermano de Joey Campbell escribe junto a su madre una emotiva carta al joven Trayvon Martin, cuyo asesinato recibió un amplio eco mediático tras la absolución del responsable, George Zimmerman, y que dio inicio al movimiento BLM en 2013.

Orange Is the New Black (2013-), quizás la más conocida de las series analizadas, tiene lugar en la penitenciaría federal de mujeres de Litchfield. Durante las cinco temporadas hasta ahora emitidas, la serie ha servido como escenario de denuncia del complejo industrial carcelario. A partir de la privatización de la prisión, deja de contemplarse la rehabilitación de las reclusas, la mayoría de ellas racializadas, y se expone la naturaleza criminal y explotadora del sistema carcelario, pues la empresa contratista, al emplearlas como mano de obra casi esclava, produce manufacturas a bajo costo. Al mismo tiempo, la empresa reduce costes en alimentación, higiene y otros ámbitos, y se muestra indiferente a un mayor uso de la fuerza por parte del personal de seguridad.

En la quinta temporada se inicia una revuelta tras el asesinato, por parte de un guardia, de Poussey, una afroamericana, lo que permite subvertir temporalmente el orden carcelario y visibilizar ciertas demandas críticas. Durante el estallido se hacen alusiones al motín en la prisión de Attica y las reclusas se organizan para vigilar a los rehenes e impedir el desalojo. La mayor parte de la temporada oscila entre momentos carnavalescos y de diversión y momentos emotivos, en los que la amiga de Poussey, Taystee, reivindica el valor de la vida de su amiga recién fallecida. Las referencias a BLM no se agotan en las demandas que Taystee exige como condición para terminar con el motín, sino que la muerte de aquélla es en sí una clara referencia al asesinato por estrangulamiento en 2014 por parte de un oficial del Departamento de Policía de Nueva York del joven afroamericano Eric Garner y cuyas últimas palabras "I can't breath" (no puedo respirar) han sido repetidas por miles de activistas afroamericanos.

En Queen Sugar (2016-) Nova Bordelon es una periodista vinculada a BLM y a organizaciones afroamericanas de carácter barrial que denuncia la corrupción del sistema policial en Nueva Orleans a partir de la detención y encarcelamiento de jóvenes menores afromericanos por delitos no violentos. Durante el episodio 2x03, Nova participa en un foro académico en un panel en torno a la encarcelación masiva de población afrodescendiente en Estados Unidos junto al epidemiólogo Robert Dubois. Mientras que Dubois hace énfasis en el impacto del encarcelamiento masivo de la población sobre la salud pública porque se generan condiciones de vulnerabilidad 
que posteriormente llegan a las comunidades afroamericanas, Nova discute los orígenes de dicha vulnerabilidad, al incidir en el cuestionamiento de quién decide qué vida es superflua o prescindible. En la discusión, ambos plantean diferentes posturas a partir de la noción de "necropolítica" propuesta por Achille Mbembe, que alude a las prácticas y estructuras que permiten la reproducción de una forma de gobierno basada en la capacidad de decisión sobre la vida de las personas en función del valor que se les confiere y que, cuando Nova y Dubois lo discuten, se puede leer en clave el grado de determinación del sistema racial sobre la vida de las personas negras: mientras que Nova no duda en definir la necropolítica como genocida y hace énfasis en las estructuras de predominio racial y la escala en el valor de la vida de las personas, Dubois reclama la capacidad de gestión de la población negra, capaz de revertir dicha situación. Este diferendo se manifiesta con mayor profundidad en los siguientes episodios cuando se muestran dos posturas frente al mundo que se revelan en tensión constante pero que llegan a articularse en un mismo plano de acción.

Asimismo, Ralph Angel, hermano de Nova, es un exconvicto y padre soltero que lucha por la custodia de su hijo menor de edad. Además de los obstáculos administrativos a los que se enfrenta para recuperar su tutela, la serie muestra las dificultades de reinserción laboral para un exconvicto, así como las prácticas discriminatorias y abusivas de los empleadores al aprovecharse de su condición de vulnerabilidad.

\section{DiversidAD SEXUAL}

El cuestionamiento de la sexualidad y las relaciones afectivas ocupa un primer plano en prácticamente todas las series señaladas. En Queen Sugar, Orange Is the New Black, Black-ish y otras como Scandal (2012-), How to Get Away with Murder (2014-), Dear White People (2017-) o She's Gotta Have It (2017-) se exploran temáticas vinculadas con relaciones poliamorosas, interraciales y homosexuales, que implican un descentramiento y puesta en cuestión del régimen afectivo-sexual monogámico y heteronormativo. La visibilización de heterogéneas prácticas sexuales y afectivas que atraviesan marcadores de raza, clase y género ha sido una constante en las series emitidas en los últimos años. En este sentido, el diálogo con BLm es evidente, puesto que desde sus inicios algunas de las figuras más representativas del movimiento como Alicia Garza o Patrisse Cullors se han declarado mujeres queer de color, y han hecho énfasis en la interseccionalidad del movimiento mediante la participación de personas queer y trans, lo cual se ha traducido en las demandas articuladas a través del mismo. La propia Cullors afirmaría que, para que el movimiento BLM avanzara, las mujeres trans negras debían comenzar a tomar decisiones sobre estrategias y tácticas (Starr, 2016). 
Otro colectivo muy activo estos años ha sido Trans Women of Color Collective (TwOCC), que ha impulsado el liderazgo, las narrativas y las experiencias de mujeres negras trans. En este sentido, resulta interesante observar cómo en las series la transexualidad ha recibido eco por medio de algunos personajes como Sophia Burset o Cotton Brown.

Sophia Burset es, en Orange Is the New Black, una mujer negra transgénero que sufre en su propio cuerpo la intersección de múltiples violencias y se refleja la manera en que operan cotidianamente las conexiones entre las luchas de género, raza y justicia social, así como la encarcelación masiva, la sobrevigilancia y la cultura del control, dimensiones que habitualmente se analizan de manera escindida (Lamble, 2015). Sophia se ve obligada a soportar no sólo el acoso del personal de seguridad de la penitenciaría, quienes le niegan las pastillas de hormonas que necesita en su transición, sino también de sus compañeras, que la discriminan por su condición trans, hasta el punto de que es aislada ilegalmente por las autoridades, lo que le impide recibir las visitas de su hijo y de su expareja.

Además de la actriz que encarna a Sophia Burset (Laverne Cox), podemos mencionar a la también transgénero Amiyah Scott, que en la serie Star interpreta a Cotton Brown. Cotton mantiene una relación conflictiva con su madre, que es incapaz de aceptar el proceso de transición de su hija. A lo largo de la serie se exponen las dificultades a las que Cotton se tendrá que enfrentar para llevar una nueva vida.

\section{EL MITO POSRACIAL, TRANSRACIALIDAD Y EL PRIVILEGIO BLANCO}

En The People v. O.J. Simpson: American Crime Story (2016) se recrea el mediático juicio al deportista afroamericano O.J. Simpson, en el que a pesar de las evidencias de ADN el exjugador de futbol americano fue absuelto por el doble homicidio de su exmujer Nicole Brown y de su acompañante Ronald Goldman. A pesar de que en el pasado O.J. Simpson había llegado a afirmar: "Yo no soy negro. Soy OJ", durante el juicio, aconsejado por su abogado Johnnie Cochran, decidió jugar "la carta racial", lo que evidenció el racismo del detective Mark Fuhrman del Departamento de Policía de Los Ángeles, quien fue la primera persona en llegar a la escena del crimen. La defensa aportó una grabación racista en la que el detective describía actos de violencia policial hacia sospechosos negros y empleaba un total de cuarentaiún veces el término peyorativo de nigger para referirse a la población negra.

Con el antecedente de los disturbios de 1992 de Los Ángeles, por los que fueron absueltos los policías que golpearon brutalmente al conductor negro Rodney King, O.J. Simpson consiguió movilizar el apoyo de la población afroamericana y en especial 
de los miembros del jurado. Este controversial caso en el que la acusación llegó a pedir a O.J. que se probara el guante manchado de sangre que se encontró en la escena del crimen, y que al no encajar en su mano llevó al abogado Johnny Cochrane a afirmar: "If it doesn't fit you must acquit" (Si no encaja, debe ser absuelto), fue transmitido por televisión, y para muchos marca el inicio de los reality shows. Sin embargo, más allá del carácter mediático del mismo, el juicio puso de manifiesto la forma en que la racialización como dispositivo permea de manera determinante la construcción de identidades y percepciones sociales en la sociedad estadunidense.

El mito de la posracialidad revela cómo de manera cotidiana la línea de color que advirtió Du Bois hace más de cien años continúa trazando las geografías y corporalidades raciales, económicas y políticas sobre las que se sostiene el régimen de dominación estadunidense. Y es que en diversas series como Dear White People, Queen Sugar o Atlanta se ha explorado cómo jóvenes afroamericanos en situación económica privilegiada son objeto de brutalidad policial, por lo que se revela la situación de vulnerabilidad a la que se exponen los cuerpos negros independientemente de otros marcadores, y que viene a explicitar los aspectos determinantes del régimen estructural de dominación racial que predomina en Estados Unidos. En estos términos, lejos del pretendido mito de la posracialidad, la raza sigue siendo un articulador esencial en la realidad cotidiana de millones de personas.

Por otra parte, resulta interesante observar cómo se ha parodiado en las series afroamericanas la negación de amplios sectores de la población blanca a reconocer la importancia primordial de la raza y de los privilegios asociados a la misma. Un primer acercamiento lo encontramos en el capítulo 1x07 de Atlanta, donde en un programa de entrevistas de la Black American Network, Harrison, un adolescente afroamericano, dice asumirse como un hombre blanco de treinta y cinco años de Colorado. El adolescente afirma no estar dispuesto a "dejar de ser quien es" y revela cómo fue consciente de su identidad a partir de la discriminación. Esta parodia en torno a la identidad transracial es una clara alusión al caso de Rachel Dolezal, una estadunidense blanca que durante décadas se autoadscribió como negra y participó en organizaciones afroamericanas como la Asociación Nacional para el Progreso de las Personas de Color (National Association for the Advancement of Colored People, NAACP). Tras quedar al descubierto su condición racial ella se defendería argumentando que la raza es una construcción social y que, por tanto, tiene un carácter contingente que vendría determinado por la autoadscripción. No obstante, esta postura ha recibido amplias críticas, en un contexto en el que los discursos de las minorías mantienen un fuerte cuestionamiento de los privilegios raciales, de la apropiación cultural y de la blanquitud.

En la serie Dear White People, Samantha White es una estudiante de la Winchester University que como locutora de radio aborda cuestiones relativas al privilegio 
blanco y la apropiación cultural. La victoria electoral de Donald Trump en Estados Unidos ha venido acompañada de una reaparición pública del supremacismo blanco que, impulsado por el movimiento Alt Right, ha popularizado conceptos como el genocidio blanco, o eslogans reaccionarios frente al auge del movimiento BLM como All lives matter o Blue lives matter (en referencia a los cuerpos policiales). La locutora se hace eco de alguna de estas frases ridiculizando y poniendo en evidencia algunos de los postulados contenidos en las mismas, así como malentendidos respecto a la lucha antirracista en Estados Unidos, pues cuestiona aspectos relativos al privilegio blanco y la apropiación cultural. Discute tópicos como "el racismo inverso", "la guerra racial" o "la construcción social de la raza". Frente a una ofensiva fiesta en que los estudiantes blancos se pintan la cara de negro (blackface) como provocación ante el trabajo en la radio de Samantha, los estudiantes negros se organizan en contra, cuestionando los privilegios de sus compañeros.

Un momento determinante al final de la primera temporada tiene lugar cuando uno de los jóvenes más combativos, Reggie, tras verse enfrentado en medio de una fiesta a otro estudiante blanco por emplear el término nigger, un policía le apunta con una pistola. En esta escena se evidencia la forma más cruda a través de la que el racismo opera cotidianamente: la brutalidad policial. En un país en el que una persona negra tiene tres veces más posibilidades de morir a manos de la policía (y en algunos estados como Oklahoma o Georgia, hasta siete veces más) ${ }^{7}$ que una persona blanca, la reflexión en torno al privilegio blanco y el racismo resulta urgente, y se esboza imprescindible para el desmantelamiento de las estructuras que hacen posible la reproducción de un capitalismo racial que sigue alimentándose de vidas negras.

\section{Conclusiones}

A pesar de que las series mencionadas apenas constituyen una pequeña parte de las muchas series televisivas de temática afroamericana que han abordado en los últimos años de manera directa o lateral el movimiento BLM o algunas de sus demandas con respecto a la brutalidad policial, el complejo industrial carcelario, la violencia sexual y la inseguridad, considero importante explorar esas interconexiones que nos pueden permitir ampliar y extender el campo de los estudios visuales y culturales, incorporando problemáticas en torno al racismo, la desigualdad y la violencia desde enfoques interdisciplinarios.

\footnotetext{
${ }^{7}$ Para consultar estadísticas se recomienda la página $<$ https://mappingpoliceviolence.org/ $>$, de donde he extraído los datos señalados.
} 
En los casos señalados la ficción y la denuncia de la realidad se articulan de manera insospechada y evidencian que, lejos de aquella degradación de la audiencia negra que Robinson preconizaba, hoy nos encontramos con públicos atentos y sensibles frente a una realidad que no sólo queda reflejada en la pantalla, sino que atraviesa sus propias vidas. El éxito de Black Panther (2017) y las discusiones que se han generado a partir de su estreno ponen de manifiesto el impacto e influencia que las imágenes y corporalidades negras en televisión tienen para el público afroamericano y la manera en que contribuyen para imaginar futuros alternativos frente a las lógicas de dominación cultural en el marco del capitalismo racial.

El movimiento de liberación negra hoy se nutre de recursos desde los cuales se pueden volver a trazar horizontes de posibilidad. Las series, en este sentido, se convierten en otra herramienta desde la que se puede enfrentar el racismo sistémico y la avanzada del supremacismo blanco. Hace relativamente poco, $\mathrm{HBO}$ anunciaba de manera controversial el futuro lanzamiento de la serie Confederate, que imagina a Estados Unidos en donde el bando confederado hubiera vencido en la Guerra Civil y la esclavitud siguiera siendo legal. El anuncio recibió fuertes críticas y Amazon respondió a los pocos días anunciando el estreno de Black America, un programa donde, como parte de la reconstrucción posbélica y como formas de reparación por la esclavitud, los afroamericanos recién liberados tras la Guerra Civil asegurarían en los estados de Louisiana, Mississippi y Alabama su libertad y soberanía para constituir el país de New Colonia. La serie, ideada por el afroamericano Will Packer, de concretarse, pondría en el centro de discusión las reparaciones históricas frente a la esclavitud. Tal y como aparece en un fragmento del manifiesto Una visión para las vidas negras: "Exigimos reparaciones por los daños actuales y pasados. El gobierno, las corporaciones responsables y otras instituciones que han sacado provecho del daño infligido a la gente negra -desde el colonialismo a la esclavitud, pasando por la negación sistemática y planificada de alimentos y viviendas, el encarcelamiento masivo y la vigilancia- deben reparar el daño cometido" (Movement for Black Lives, 2016: 229).

La difusión en el debate público de las demandas centrales del movimiento BLM a través de las series de televisión constituye un antes y un después en el imaginario afroamericano en Estados Unidos. Lejos de los sórdidos inicios del cine estadunidense, en donde hace poco más de un siglo se estrenaba El nacimiento de una nación de D.W. Griffith, una película en la que aparecen miembros de Ku Klux Klan en defensa de la nación y personas pintadas de negro, hoy, por medio de la interacción entre productores, actores y público negro, se traza en la televisión una trayectoria histórica y cultural alternativa al colonialismo y al racismo, aunque las posibilidades vengan determinadas por el formato comercial y el acceso privado a los contenidos. 
Aunque no podamos aventurarnos en este punto, no podemos negar la posibilidad de que este camino pueda ser desbordado por nuevas iniciativas audiovisuales de carácter independiente y autónomo que, más allá de las exigencias del mercado, vengan a impulsar nuevas formas democráticas de acceso, uso y difusión que mantengan una crítica interseccional congruente, tanto en el plano de la forma como de los contenidos, extendiendo la potencialidad de autorrepresentación y autodeterminación desde miradas propias y antagónicas al capitalismo racial.

\section{VIDEOGRAFía}

Atlanta, dir. por Hiro Murai et al., Estados Unidos, Fx Productions/MGMT Entertainment, 2016.

Dear White People, dir. por Justin Simien et al., Estados Unidos, SisterLee Productions /Culture Machine/Code Red Productions / Homegrown Pictures/Roadside Attractions/Lionsgate Television, 2017.

Empire, dir. por Sanaa Hamri et al., Estados Unidos, Imagine Television/Lee Daniels Entertainment/Danny Strong Productions / Little Chicken Productions / 20th Century Fox Television, 2015.

How to Get Away with Murder, dir. por Bill D'Elia et al., Estados Unidos, Shondaland/ Nowalk Entertainment/ABC Studios, 2014.

Inside Look: The People v. O.J. Simpson, American Crime Story, dir. por Joel Knoernschild, Estados Unidos, FX Network/More Media, 2016-2017.

Luke Cage, dir. por Andy Goddard et al., Estados Unidos, ABC Television Studio/ ABC Domestic Television/Marvel Entertainment/Marvel Studios/Marvel Television/Netflix/The Walt Disney Company, 2016.

Orange is the New Black, dir. por Andrew McCarthy et al. , Estados Unidos, Tilted Productions / Lionsgate Television, 2013.

Power, dir. por Sanford Bookstaver et al., Estados Unidos, CBS Television Studios, 2014. 
Queen Sugar, dir. por Kat Candler et al., Estados Unidos, Harpo Productions / Warner Horizon Television, 2016.

Roots, dir. por Bruce Beresford et al., Estados Unidos, Film Afrika Worldwide/History Channel/ The Wolper Organization/Will Packer Productions, 2016.

Scandal, dir. por Tom Verica et al., Estados Unidos, Shondaland/ABC Studios, 20122018.

She's Gotta Have It, dir. por Spike Lee, Estados Unidos, 40 Acres and a Mule Filmworks / Tonik Productions, 2017.

Shots Fired, dir. por Gina Prince-Bythewood et al., Estados Unidos, Undisputed Cinema/Imagine Television/20 $0^{\text {th }}$ Century Fox Television, 2017.

Star, dir. por Paul McCrane et al., Estados Unidos, Lee Daniels Entertainment $/ 20^{\text {th }}$ Century Fox Television, 2016.

The Get Down, dir. por Ed Bianchi et al., Estados Unidos, Bazmark Films / Sony Pictures Television, 2016-2017.

Underground, dir. por Anthony Hemingway, Estados Unidos, Get Lifted Film Company/Safehouse Pictures-Sony Pictures Television, 2016.

\section{FueNTES}

BUTLER, B.

2016 "How TV Tackled Racial Issues in the Black Lives Matter era of 2016", The Washington Post, 27 de diciembre, en <https://www.washingtonpost.com/ news / arts-and-entertainment / wp/ 2016/12 / 27 / how-tv-tackled-black-livesmatter-in-2016/ ?noredirect=on\&utm_term $=.07336666 c 4 f 5>$, consultada el 3 de agosto de 2017.

GuERRERO, ED

2012 Framing Blackness: The African American Image in Film, Temple University Press. 
Kelley, Robin Davis Gibrain

2017 "What Did Cedric Robinson Mean by Racial Capitalism?", enero, en $<$ http: / / bostonreview.net / race/ robin-d-g-kelley-what-did-cedric-robinson-mean-racial-capitalism>, consultada el 3 de agosto de 2017.

KRASZEWSKI, JONATHAN

2002 "Recontextualizing the Historical Reception of Blaxploitation: Articulations of Class, Black Nationalism, and Anxiety in the Genre's Advertisements", Velvet Light Trap, 50, pp. 48-61.

LAMBLE, SARAH

2015 “Transforming Carceral Logics: 10 Reasons to Dismantle the Prison Industrial Complex Using a Queer/Trans Analysis", en Eric A. Stanley y Nat Smith, eds., Captive Genders: Trans Embodiment and the Prison Industrial Complex, AK Press, pp. 235-266.

Movement for Black Lives

2016 “Una visión para las vidas negras. Demandas políticas para el poder negro, la libertad y la justicia", en Nuevo activismo negro. Lecturas y estrategias contra el racismo en Estados Unidos, Buenos Aires, Tinta Limón, pp. 225-232.

ONGIRI, Amy ABugo

2009 Spectacular Blackness: The Cultural Politics of the Black Power Movement and the Search for a Black Aesthetic, University of Virginia Press.

Raiford, Leigh y Heike Raphael-Hernandez, eds.

2017 Migrating the Black Body: The African Diaspora and Visual Culture, University of Washington Press.

ReID, Mark A.

2000 "New Wave Black Cinema in the 1990s", en Wheeler Winston Dixon, Film Genre. New Critical Essays, State University of New York Press, pp. 13-28.

ROBINSON, CEDRIC J.

1998 "Blaxploitation and the Misrepresentation of Liberation", Race E Class, vol. 40, no. 1, pp. 1-12.

1983 Black Marxism: The Making of the Black Radical Tradition, University of North Carolina Press. 
StARr, TERRELl JERMAINE

2016 "La violencia contra las mujeres transgénero negras", en Varios autores, Nuevo activismo negro. Lecturas y estrategias contra el racismo en Estados Unidos, Buenos Aires, Tinta Limón, pp. 167-169.

TAYLOR, KEEANGA-YAMAHTTA

2017 Un destello de libertad. De \# BlackLivesMatter a la liberación negra, Madrid, Traficantes de sueños.

TERRY, JOHN ROBERT

2012 "Towards the Gendering of Blaxploitation and Black Power", Madison Historical Review, vol. 9, article 5, pp. 79-105. 